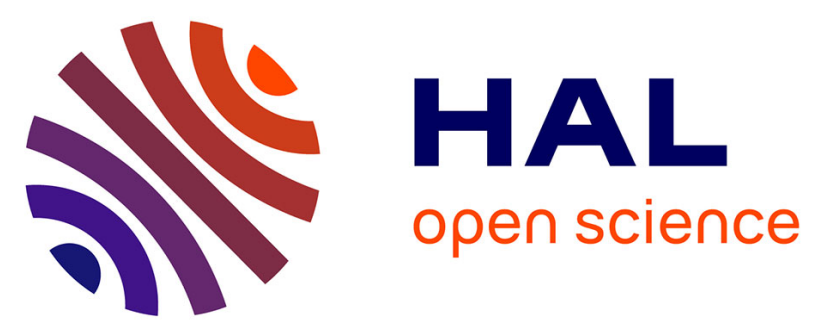

\title{
Defining the indigenous ranges of species to account for geographic and taxonomic variation in the history of human impacts: reply to Sanderson 2019
}

\author{
P.J. Stephenson, Molly K Grace, H. Resit Akçakaya, Ana S.L. Rodrigues,
} Barney Long, David P Mallon, Erik Meijaard, Jon Paul Rodriguez, Richard P.

Young, Thomas M. Brooks, et al.

\section{To cite this version:}

P.J. Stephenson, Molly K Grace, H. Resit Akçakaya, Ana S.L. Rodrigues, Barney Long, et al.. Defining the indigenous ranges of species to account for geographic and taxonomic variation in the history of human impacts: reply to Sanderson 2019. Conservation Biology, 2019, 33 (5), pp.1211-1213. 10.1111/cobi.13400 . hal-02383457

\section{HAL Id: hal-02383457 https://hal.science/hal-02383457}

Submitted on 7 Dec 2020

HAL is a multi-disciplinary open access archive for the deposit and dissemination of scientific research documents, whether they are published or not. The documents may come from teaching and research institutions in France or abroad, or from public or private research centers.
L'archive ouverte pluridisciplinaire HAL, est destinée au dépôt et à la diffusion de documents scientifiques de niveau recherche, publiés ou non, émanant des établissements d'enseignement et de recherche français ou étrangers, des laboratoires publics ou privés. 


\title{
Defining the indigenous ranges of species to account for geographic and taxonomic variation in the history of human impacts: reply to Sanderson 2019
}

\author{
P.J. Stephenson ${ }^{1}$, Molly K. Grace ${ }^{2}$, H. Resit Akçakaya ${ }^{3}$, Ana S. L. Rodrigues ${ }^{4}$, Barney Long ${ }^{5}$, \\ David P. Mallon ${ }^{6}$, Erik Meijaard ${ }^{7}$, Jon Paul Rodriguez ${ }^{8}$, Richard P. Young ${ }^{9}$, \\ Thomas M. Brooks ${ }^{10}$, and Craig Hilton-Taylor ${ }^{11}$
}

\author{
${ }^{1}$ International Union for Conservation of Nature Species Survival Commission, Species Monitoring Specialist \\ Group, CH-1276, Gingins, Switzerland, email stephensonpi@gmail.com \\ ${ }^{2}$ Department of Zoology, University of Oxford, Oxford, OX1 3SZ, U.K. \\ ${ }^{3}$ Department of Ecology and Evolution, Stony Brook University, Stony Brook, NY 11794, U.S.A. \\ ${ }^{4}$ Centre d'Ecologie Fonctionnelle et Evolutive, UMR5175 (CNRS-Université de Montpellier-UPVM-EPHE) \\ 34293, Montpellier, France \\ ${ }^{5}$ Global Wildlife Conservation, 1250 24th St NW, Washington, D.C. 20037, U.S.A. \\ ${ }^{6}$ Division of Biology and Conservation Ecology, Manchester Metropolitan University, Chester Street, \\ Manchester, M1 5GD, U.K. \\ ${ }^{7}$ Durrell Institute of Conservation and Ecology, Marlowe Building, University of Kent, Canterbury, Kent CT2 7NR, \\ U.K. \\ ${ }^{8}$ IUCN Species Survival Commission, Instituto Venezolano de Investigaciones Científicas and Provita, Caracas, \\ Venezuela \\ ${ }^{9}$ Durrell Wildlife Conservation Trust, Les Augres Manor, Jersey, JE3 5BP, U.K. \\ ${ }^{10}$ IUCN, CH-1196, Gland, Switzerland \\ ${ }^{11}$ IUCN Red List Unit, Pembroke Street, Cambridge CB2 3QZ, U.K.
}

Article impact statement: Accounting for taxonomic and geographic variation in historic human impacts on indigenous range will facilitate use of IUCN's Green List of Species. 
The International Union for Conservation of Nature (IUCN) is in the process of developing a Green List of Species that will provide a standardized framework for measuring species' recovery and documenting the impact of conservation action. Last year, we and other members of the IUCN Species Survival Commission Species Conservation Success Task Force published an article describing the conceptual vision for the Green List of Species and introducing the rationale and proposed assessment method (Akçakaya et al. 2018). The purpose of the publication was to encourage field testing and discussion among the broader scientific community and thus facilitate further development and refinement of the Green List of Species prior to formal adoption by IUCN. We are therefore grateful for Sanderson's (2019) contribution to the discussion on how best to operationalize this new tool, the focus of which was the challenge of delineating a species' indigenous range.

The Green List of Species introduces new metrics such as conservation legacy and recovery potential that require the estimation of the indigenous range of the species being assessed (and possibly the projected range because it is shaped by ongoing and future climate and environmental change). The IUCN (2013) defines indigenous range as "the known or inferred distribution generated from historical records, or physical evidence of the species' occurrence. Where direct evidence is inadequate ... the existence of suitable habitat within ecologically appropriate proximity to observed range may be taken as adequate evidence of previous occupation." Akçakaya et al. (2018) suggest that, for assessments to be comparable across taxonomic groups, it is necessary to estimate indigenous range at a specific past date. However, species' distributions change over time (through both natural and anthropogenic processes), so operationalizing this definition for the purposes of the Green List of Species requires clarification of the choice of, and need for, a corresponding benchmark date.

Sanderson summarizes the issues around the choice of benchmark date used to define indigenous range in the context of the Green List of Species. He argues that the potential dates proposed as options by Akçakaya et al. (2018) - 1500 (the year from which the IUCN Red List of Threatened Species considers extinctions and the approximate start of European expansion) or 1750 (the beginning of the Industrial Era as defined by the Intergovernmental Panel on Climate Change)-are inappropriate because they come from a Euro-centric perspective. He recommends, instead, setting the date to "a time before human beings were the most important element limiting species' distributions," which would allow assessors to choose a reference date of local relevance to the species being assessed, depending on the environmental and human history specific to the region under consideration. As examples of locally relevant benchmark dates (i.e., anthropogenic tipping points for biodiversity), Sanderson proposes 2500-3500 years BP for Polynesian species, approximately 2,000 years BP for lions that once inhabited Greece, and the 1700 s for New Zealand species, illustrating the global variability in the timing of human impact.

Ultimately, the Green List of Species aims to measure species' status and recovery relative to a baseline prior to (major) human impacts. We agree with Sanderson that there are challenges and disadvantages in calculating a common date against which all species should have their indigenous range benchmarked. The earlier the chosen date, the better it corresponds to a prehumen impact benchmark, but the scarcer the available data for reconstructing the species' ranges. The possible dates originally suggested by Akçakaya et al. (2018) (1500 and 1750) are compromises in this trade-off and are framed by pragmatic considerations, such as the likelihood of data availability, standardization and guidance facilitation, alignment with the IUCN Red List of Threatened Species, facilitation of comparability among and between taxonomic groups, and limiting risk of system manipulation (e.g., through the selection of more recent baseline dates as a means of making recovery targets easier to attain). If assessors need to choose their own benchmark date to calculate indigenous range for each 
species individually, the Green List of Species assessment process may become confusing, challenging, and inconsistent across taxa and regions. Lengthy peer review and consultation processes may also be needed to standardize assessments, which would slow the process and hamper target setting and conservation planning. The suggestion to use dates of local relevance also poses a unique problem for widely distributed species. In the case of a species such as the Osprey (Pandion haliaetus), which is found on multiple continents (each with its own history of human impact), choosing a benchmark date could be difficult and subjective.

However, we agree with Sanderson (2019) that the dates that mark the beginning of anthropogenic effects on indigenous range are not the same for lions in Europe and Africa, a bird on a Polynesian island, or a frog in New Zealand. For this reason, setting a common global benchmark would result in uneven recovery ambitions for different regions of the world. For example, by 1850 the distributions of many species had already been significantly curtailed by industrialization in Europe, but much less so in Africa. Therefore, using 1850 as a universal benchmark date would likely make it easier to restore species' ranges to this benchmark in Europe than in Africa.

We therefore urge pragmatism. We need to balance the desire to select dates of local relevance to the species assessed against the feasibility of assessing numerous species in a comparable fashion. While allowing assessors to define their own benchmark date could prove problematic, a universal, predefined date will not suit everyone and may even discourage assessors who cannot find data for a specific period. We are thus considering the option that the Species Conservation Success Task Force should consult environmental historians (as suggested by Sanderson) and use historical data (e.g., Ellis et al. 2010; Faurby \& Svenning 2015) to recommend a date for each continent, or possibly each region or subregion within a continent, as appropriate. Hypothetically, following Sanderson's example, 1700 could be set as the benchmark for Oceania generally, but an earlier date might be appropriate for Polynesia. A further possibility to explore is that, within this general framework, assessors could adapt proposed dates for a given geography based on available knowledge of the timing of impacts on different taxa. In Hawaii, for example, people probably first settled the islands about 3,000 years BP (Pearce \& Pearce 2010), which may be a suitable benchmark date for taxa such as birds, but snail populations were only affected significantly from 1955 with the introduction of an invasive carnivorous snail (Regnier et al. 2009). Clear criteria for adjusting preset dates-as well as written justification for the benchmark chosen in each assessment- will be needed to maintain consistency while allowing flexibility. Guidance will have to be produced to deal with complicated issues, such as what to consider as human impact and how to benchmark species that are widespread across continents. Although Sanderson's suggestion of choosing a date at which more than $5 \%$ of a species' range has been affected might address the latter issue, it might also add too much complexity to the assessment process.

We expected that many ideas proposed in Akçakaya et al. (2018) would evolve as the result of scrutiny from the wider scientific community. To move the debate forward, we are actively working with partners in several organizations to test the Green List of Species assessment method on a variety of plant, fungus, and animal taxa and to identify necessary modifications. Because species recovery is more likely to succeed with stakeholder coordination around shared goals and management plans (Crees et al. 2016), we are working to ensure the Green List of Species is relevant to local users; Sanderson's comments are a useful contribution in this regard. Additionally, we are consulting across regions and disciplines to identify tools and data sets that will facilitate estimation of indigenous and projected range. We are also comparing maps of historical land use with species records to gain a better understanding of the implications of different continental and global benchmark dates. An enduser survey will further help us shape the final design. 
We welcome Sanderson's critique of the benchmarking of species' indigenous ranges and believe that a balance between science and pragmatism would be apposite. Providing flexibility in the IUCN Green List of Species to take into account taxonomic and geographic variation in the history of human impacts affecting indigenous range will facilitate broad adoption and use of this global conservation tool while maintaining scientific consistency.

\section{Literature Cited}

Akçakaya HR, et al. 2018. Quantifying species recovery and conservation success to develop an IUCN Green List of Species. Conservation Biology 32:1128-1138.

Crees JJ, et al. 2016. A comparative approach to assess drivers of success in mammalian conservation recovery programs. Conservation Biology 30:694-705.

Ellis EC, Goldewijk KK, Siebert S, Lightman D, Ramankutty N. 2010. Anthropogenic transformation of the biomes, 1700 to 2000. Global Ecology and Biogeography 19:589-606.

Faurby S, Svenning JC. 2015. Historic and prehistoric human-driven extinctions have reshaped global mammal diversity patterns. Diversity and Distributions 21:1155-1166.

IUCN (International Union for Conservation of Nature). 2013. Guidelines for reintroductions and other conservation translocations. IUCN Species Survival Commission, Gland, Switzerland.

Pearce CEM, Pearce FM. 2010. Oceanic migration: paths, sequence, timing and range of prehistoric migration in the Pacific and Indian Oceans. Springer Science \& Business Media, London.

Régnier C, Fontaine B, Bouchet P. 2009. Not knowing, not recording, not listing: numerous unnoticed mollusk extinctions. Conservation Biology 23:1214-1221.

Sanderson EW. 2019. A full and authentic reckoning of species ranges for conservation. Conservation Biology. 